\title{
A MEMÓRIA NOS TEXTOS INICIAIS DE FREUD
}

\author{
Wallace da Costa Brito \\ Universidade Federal Rural do Rio de Janeiro \\ FernandaCanavêz \\ Universidade Federal Rural do Rio de Janeiro
}

\begin{abstract}
Resumo
O artigo objetiva investigar a memória no pensamento freudiano, tomando por base alguns textos daquela que é considerada sua fase pré-psicanalítica. Postula-se a importância dessa temática dentro do conjunto mais amplo da sua inovadora concepção acerca da subjetividade. Trata-se de estudo teórico-conceitual que tem um caráter ensaístico e adota como procedimento a revisão bibliográfica. Notamos que para Freud, desde os primeiros anos de suas pesquisas, a memória se configurou como um elemento notável para a compreensão do psiquismo. Destaca-se, assim, a memória enquanto tema relevante em seu pensamento, bem como sua originalidade em compreendê-la como revestida e permeada pelo inconsciente.
\end{abstract}

Palavras-chave: memória; lembrança, esquecimento; subjetividade; pensamento freudiano.

\section{THE MEMORY IN THE FREUD'S INITIAL WRITINGS}

\begin{abstract}
The article investigates the memory in Freudian thought, based on some texts of what is considered his pre-psychoanalytic phase. Posits the importance of this theme within the broader set of its innovative conception of subjectivity. It is a theoretical and conceptual study with an essayistic character, which adopts the procedure of the literature review. We note that for Freud, since the early years of his research, memory is a remarkable element for understanding the psyche. Therefore, memory is highlighted as an important theme in his thought as well as its originality in understanding it as embodied and permeated by the unconscious.
\end{abstract}

Keywords: memory; remembrance, forgetfulness; subjectivity; Freudian thought.

\section{LA MEMORIA EN LOS TEXTOS INICIALES DE FREUD}

\section{Resumen}

El artículo investiga la memoria en el pensamiento de Freud, sobre la base de algunos textos de lo que se considera su fase pre-psicoanalítica. Postula la importancia de este tema dentro del conjunto más amplio de su concepción innovadora de la subjetividad. Es estudio teórico y conceptual que tiene un carácter ensayístico y adopta el procedimiento de la revisión de la literatura. Observamos que para Freud, desde los primeros años de su investigación, la memoria se configura como un elemento notable para la comprensión de la psique. Es de destacar tanto la memoria como un tema importante en su pensamiento y su originalidad in comprenderla como cubierta y penetrada por el inconsciente.

Palabras clave: memoria; rememoración, olvido; subjetividad; pensamiento freudiano.

\section{INTRODUÇÃO}

O artigo tem por objetivo investigar a memória no pensamento freudiano, naquela que é considerada sua fase inicial (pré-psicanalítica), postulando tal temática como uma importante questão no conjunto da inovadora concepção de Freud acerca da subjetividade. Deve-se esclarecer, desde logo, que Freud possui 
um longo e denso trabalho escrito ao longo de décadas entre o final do século XIX e os anos 1930. Sua obra é reconhecidamente marcada por distintas etapas em que a partir do trabalho clínico, intimamente entrelaçado às suas produções teóricas, promovem-se revisões e tomadas de posição complementares ou mesmo diferentes, reformulando por vezes as diversas questões investigadas. Nos limites deste texto, trataremos de apresentar algumas assertivas acerca da memória no pensamento freudiano em uma etapa na qual a psicanálise se encontrava ainda não sistematizada, muito embora já apresentasse algumas formulações iniciais, pois como é conhecido, a psicanálise teve como marco inaugural, enquanto teoria e método, o livro $A$ interpretação dos sonhos (1900/1996).

Freud iniciou seu trabalho e sua obra escrita no cenário cultural europeu do final do século XIX, notavelmente marcado pelas diretivas modernas, onde as categorias da racionalidade científica eram aquelas que se destacavam. Batista (2007) descreve como características fundamentais da modernidade o surgimento da ciência e do ser humano dotado de racionalidade, consciência de si e autonomia, o que recebe o nome generalista de sujeito. Para Birman (2006), a estruturação da modernidade representou o autocentramento do sujeito no eu e na consciência com fundamento no discurso metafísico desde a filosofia de Descartes e com a tradição que se seguiu depois ele. Desse modo, a modernidade se centra no indivíduo, sendo a individualidade o que fundamentalmente define seu ideário, não havendo como nela pensar sem essa categoria. O projeto moderno é antropológico e antropocêntrico, precisamente porque o ser humano, enquanto indivíduo, passou a ocupar o lugar primeiro na medida de todas as coisas. A instituição do indivíduo como categoria prioritária e o peso de centralidade a ele atribuído pela modernidade são explicados pelo psicanalista:

Podemos caracterizar a modernidade pela construção do indivíduo como tal. Se é óbvio que antes da modernidade este era reconhecido em sua existência empírica, isso não implicava, contudo, nem uma ontologia nem uma antropologia. Ao contrário, o indivíduo estava inscrito em uma concepção holística do mundo, subsumindo à totalidade do cosmos, tanto nas tradições da Antigüidade grega e romana como no cristianismo. Em contrapartida, com a modernidade, é o indivíduo que está em questão, rompendo com as amarras limitadoras do holismo e do cosmos e se expandindo em sua existência (Birman, 2006, p. 39-40).

Inserido no contexto cultural que levou tal forma de ser ao ápice, Freud empenhou-se no estudo acerca da subjetividade ao destinar grande parte de sua vida às investigações sobre a constituição e funcionamento do psiquismo, notabilizando-se, por essa via, como crítico dos mais perspicazes em relação à cultura em que vivera. Por isso é reconhecido mais decisivamente como modernista. O movimento modernista localizado entre o fim do século XIX e o início do século XX é definido por Birman (2006) como uma espécie de sintoma 
da própria modernidade. Com uma interessante interpretação psicanalítica de tal movimento cultural, o autor aponta para o outro lado em que há o retorno funesto para o que a modernidade pretensiosamente tentou rejeitar, a saber: a suposta soberania e autonomia do sujeito, ao conceber que este teria como núcleo de si mesmo o eu e a consciência. Birman (2006), aliás, aponta o modernismo como movimento crítico da modernidade desenvolvido por diretivas distintas a esta. Movimento onde o campo dos signos é alterado e os eixos norteadores da modernidade são invertidos. Inserido em tal contexto, Freud foi aquele que apontou para a descentralidade da consciência e do eu em relação às pulsões e à sexualidade, concebendo o inconsciente como fonte proeminente a emanar força no psiquismo.

Tendo isso em mira, adiante refletiremos especificamente sobre a memória inserida na complexa trama da constituição da subjetividade tal como realizada por Freud quando se propôs pesquisar o sujeito e suas formas de padecimento psíquico. A memória se caracterizou como um importante elemento para Freud investigar algumas dentre as respostas que buscava acerca da subjetividade. De tal modo que alguns comentaristas da obra freudiana, como Antonello e Herzog (2012), consideram a memória como tema a ocupar um lugar central na estrutura teórico-clínica do pensamento freudiano.

\section{MÉTODO}

Trata-se de estudo teórico-conceitual que tem um caráter ensaístico. Como tal, adota como procedimento a revisão bibliográfica. $O$ texto apresenta estilo hermenêutico, uma vez que versa sobre tema passível de interpretação, reconhecendo o empenho que se espera da leitura de escritos complexos que demandam um estudo (Japiassú \& Marcondes, 2006). Desse modo, tece leituras que buscam extrair considerações e indicativos que forneçam as bases inteligíveis para discutir o problema levantado. O pensamento freudiano é tomado como referência por ser entendido como marcado por um posicionamento crítico e por ter se configurado como um campo de visão inovador acerca da subjetividade, implicando, consequentemente, em uma chave de leitura original sobre a memória.

\section{RESULTADOS E DISCUSSÕES}

A psicanálise, escreve Garcia-Roza (2008), compôs-se como um modo peculiar de conceber o sujeito ao considerar a subjetividade clivada, ou seja, marcada pela divisão em dois grandes sistemas: Inconsciente (Ics) e Préconsciente/Consciente (Pcs/Cs). Seu sentido, porém, remete ao Inconsciente. Essa concepção da subjetividade é radicalmente distinta daquela que fora pensada por Descartes nos primórdios da modernidade, uma vez que na 
perspectiva do filósofo, trata-se de uma subjetividade psicológica integrada e assimilada na consciência. Na psicanálise, diversamente, a subjetividade clivada funciona por duas ordens díspares e uma dessas ordens, a inconsciente, a estabelece e constitui. Há, portanto, algo inovador no pensamento freudiano em sua concepção do sujeito; algo que segundo Garcia-Roza (2008), a coloca distante tanto da psicologia quanto da filosofia, não no sentido de superioridade, mas de uma notável diferença.

Como descreve Garcia-Roza (2008), o inconsciente tal como conceituado pelo precursor da psicanálise resultou em uma leitura manifestamente inédita acerca da subjetividade. O que acarretou implicações no estudo da memória. Segundo Canavêz (2012), Freud, incessantemente, aponta os registros por onde a memória funciona, a saber, o inconsciente e o consciente. Ao longo de sua trajetória, no extenso processo de formulação da teoria psicanalítica sempre inseparável de sua atuação clínica, ele investigou o psiquismo e construiu uma concepção do aparelho psíquico; e a memória encontrou lugar no conjunto de suas concepções, recebendo sua atenção. Vale frisar que a teoria inaugurada por Freud se entrelaça com intimidade à sua prática clínica, em meio a qual o fato constante de os pacientes não manifestarem certas lembranças (relacionadas a conteúdos sexuais) terminaram por despertar seu olhar atento, levando-o a postular uma abordagem incipiente sobre a memória em sua ligação às psiconeuroses, cujo esboço explicativo se encontra na Carta 52 escrita em 1896 a seu interlocutor, Fliess. Desse modo, Freud aventurou-se por uma extensa e exigente empreitada, inaugurando uma nova forma de conceber o sujeito. Ao longo de sua obra, diversos textos se ocupam em compreender a memória, de modo que é possível afirmar que esta aparece como importante tema na construção de sua teoria. Dentre os escritos de Freud nos quais podemos encontrar a memória enquanto tema central ou senão exatamente assim, ao menos como elemento importante, dentre outros, destacamos os seguintes: Projeto para uma psicologia científica (1895/1996); Carta 52 (1896/1996); O mecanismo psíquico do esquecimento (1898/1996); Lembranças encobridoras (1899/1996); A interpretação dos sonhos (1900/1996) - em especial o capítulo sete; Leonardo da Vinci e uma lembrança de sua infância (1910/1996); Recordar, repetir e elaborar: novas recomendações sobre a técnica da psicanálise (1914/1996); Os instintos e suas vicissitudes (1915/1996); Repressão (1915/1996); O inconsciente (1915/1996); Além do princípio do prazer (1920/1996); Uma nota sobre o bloco mágico (1925/1996); Construções em análise (1937/1996).

Ao longo da fase considerada pré-psicanalítica ganha força a suspeita de Freud de que um estudo para poder de fato chegar a uma melhor compreensão do modo de funcionamento da mente não poderia se restringir às explicações em voga na psicologia, alinhadas e limitadas à consciência. Como é sabido, o pai da psicanálise surpreenderá ao sistematizar sua teoria elegendo por objeto o 
inconsciente. De acordo com Garcia-Roza (2008), Freud organiza e apresenta a concepção de inconsciente no capítulo sete de $A$ interpretação dos sonhos (1900/1996). Nos termos originais aferidos por Freud, o Inconsciente é um sistema psíquico adverso a outro, o sistema Pré-consciente/Consciente, diferenciando radicalmente a teoria psicanalítica da psicologia da consciência.

Ao propor o inconsciente enquanto sistema de fato relevante para a leitura do psiquismo, Freud articula uma concepção inovadora na leitura sobre o sujeito. Inovadora não só em relação à psicologia, à medicina e à ciência, como para a própria história do pensamento. Enquanto nas construções teóricas daqueles que foram os pilares do pensamento moderno, tal como Descartes, que concebeu a consciência, o eu e a razão enquanto "lugar" da verdade no sujeito, Freud concebe o eu e a consciência como sendo o que de fato oculta sua verdadeira condição. Até então concebido de acordo com a identificação com sua consciência, desde Freud aparece a importante questão sobre o sujeito do inconsciente em sua ligação com o sujeito consciente. Sujeito marcadamente dividido, isto é, cindido entre duas ordens díspares dentro de si mesmo. Como escreve Garcia-Roza (2008), com Freud o que se almeja é tornar explícita a lógica do inconsciente e o desejo que a impulsiona.

No interior dessa questão mais ampla acerca do funcionamento do psiquismo e da consequente constituição subjetiva, desde os primeiros anos de seu trabalho, o pai da teoria psicanalítica parece ter entendido que sobre o tema da memória repousariam importantes achados a serem explorados. Assim, ele introduz um novo jeito de pensar sobre a memória. Podemos observar isso, por exemplo, em $A$ interpretação dos sonhos (1900/1996), obra na qual a concepção da primeira tópica do aparelho psíquico estruturado nos sistemas Inconsciente e Pré-consciente/Consciente vincula a memória ao sistema Inconsciente através dos traços mnêmicos e representações.

Ferrarini e Magalhães (2014) ressaltam que se deve levar em conta que a memória e suas distintas manifestações psíquicas figurou entre as inquietações de Sigmund Freud, levando-o a indagar sobre o seu funcionamento nos mais diversos momentos de sua obra. Ao longo desta, sua compreensão se expande desde o âmbito individual/funcional até o sociocultural, tornando-se um dos pilares teóricos da psicanálise. Aliás, as autoras destacam que ao percorrermos as formulações freudianas podemos identificar tal conceito enquanto memória social. Tal afirmativa talvez seja um tanto quanto incomum àqueles menos familiarizados com o pensamento freudiano e com a psicanálise, uma vez que de maneira muito comum, pensam que se trata de teorização estritamente direcionada ao que podemos chamar de âmbito individual. Tal modo de entender, entretanto, como argumentam Ferrarini e Magalhães (2014), é equivocado e soa no mínimo como simplista. As questões referentes notadas como concernentes ao âmbito cultural foram presentes no pensamento freudiano e a memória enquanto tema de seu interesse não escapou a essa premissa. A 
memória se dá ou se faz de modo relacional, uma vez que o inconsciente se constrói e altera nas vivências em que os outros tomam parte conosco. Isso quer dizer que o inconsciente não é exatamente uma instância restrita a um sujeito em separado dos demais. A memória, em específico, nesse sentido, não se constrói nem funciona sem a presença ou participação do outro. Acerca desse entrelace relacional que figura como indelével a todo e qualquer sujeito do inconsciente, mostra-se esclarecedora a argumentação tecida por Canavêz (2012) quando aponta para o fato de que na trama conceitual da psicanálise, desde o seu início, estão mutuamente implicados o sujeito e sua cultura, assim como o sintoma e o social, devendo ser problematizadas as declarações que porventura os entendam e coloquem apartados.

Ainda conforme Canavêz (2012), há no pensamento freudiano, em sua dedicação à construção teórica sobre o aparelho psíquico, uma investigação consistente sobre a memória. A psicanálise seria um saber que restituiria o que restou perdido entre o que passou e o presente. Haveria um passado posto de lado, relegado a um lugar obscuro do psiquismo, só que, de fato, não esquecido. $E$ não esquecido porque $O$ inconsciente pelo qual nos constituímos opera ativamente no psiquismo e é por ele que entrelaçamos o que passou e o que se passa conosco. Na formulação do aparelho psíquico, Freud, em sua originalidade de pensamento, tal como coloca Santos (2008), concebe a memória em sua relação com os registros de caráter inconsciente. Pela determinação inconsciente, a memória se apresenta ao longo de vezes diversas, pois os traços mnêmicos sofrem retranscrições. Para Antonello e Herzog (2012), Freud apresenta como conteúdo do aparelho psíquico os signos que se inscrevem e reinscrevem, sinalizando que seu acesso se dá por diversos momentos da vida e cada um desses acessos acarreta retranscrições.

Temos então que Freud chegou a notar, desde os primeiros anos de seu trabalho investigativo sobre o sujeito, que suas pesquisas não poderiam descuidar da memória. Em seu trabalho clínico, as vivências infantis relatadas por seus pacientes foram progressivamente lhe chamando a atenção. O que parece ter sido decisivo para que Freud valorizasse esse período da vida como fundamental para suas construções conceituais e seu método de trabalho clínico. Nessa perspectiva, Zavaroni, Viana e Celes (2007) destacam que ao longo da história do movimento psicanalítico a infância se mostra como um importante tema. Desde o início de suas investigações - no trabalho clínico - a evocação das vivências infantis pelos pacientes termina por chamar a atenção do precursor da psicanálise. Não sem motivo, Freud inaugurou uma elaboração teórica ímpar com base na escuta dos relatos referentes aos anos iniciais de vida dos pacientes. $O$ entendimento da psicanálise em relação aos relatos dessa fase da vida consiste em promover o resgate não do fato tal como tenha mesmo ocorrido, como se fosse uma reprodução fiel, mas a maneira peculiar como foi inscrito no psiquismo, vindo a direcionar a constituição do sujeito como também a maneira 
como este evoca o passado. A infância na vida psíquica do sujeito se estabelece em dupla direção, a constituição do sujeito enquanto tal e a interpretação sobre tal constituição. Isso quer dizer que as vivências infantis são fundamentais para a constituição subjetiva tal como cada um de nós a realiza e, também, pelo modo como passamos a sentir, pensar, compreender, falar e, claro, lembrar mas também esquecer sobre tal constituição, a qual não é conscientemente realizada.

Para Caropreso (2006), a formulação de uma teoria sobre a memória e sua ligação com a percepção e a consciência foram o problema nuclear dos estudos metapsicológicos realizados por Freud, desde as origens. Quando Freud começa a desvincular a ideia de que o psíquico seria equivalente ao consciente, isto é, quando começa a propor que o aparelho psíquico é estruturado por diversos sistemas, a vinculação entre memória, percepção e consciência se torna alvo de seu questionamento e investigação. O que ocorrerá ao longo de diversos de seus escritos, desde $O$ projeto para uma psicologia científica (1895/1996) e, poucos anos depois, em $A$ interpretação dos sonhos (1900/1996), chegando até mesmo a estar presente na elaboração da segunda tópica em 1920. Os aparelhos freudianos, em suas distintas variantes: aparelho de linguagem, aparelho neuronal, como nas duas configurações do aparelho psíquico são, primeiramente, teorias sobre a memória. Sabe-se que Freud, conforme as etapas de seu trabalho, concebeu leituras distintas acerca da mente. Sabemos igualmente que sua formação em medicina com especialidade em neurologia exerceu influência em suas elaborações iniciais. Conforme desenvolvia sua originária pesquisa, paulatinamente, ocorreu uma passagem do Freud neurologista ao Freud psicanalista, resultando com isso na gradativa modificação da sua compreensão e concepção teórica. Não à toa, o aparelho neuronal é a concepção adotada no Projeto para uma psicologia científica (Freud, 1895/1996). Assim sendo, as variantes do aparelho psíquico são duas, primeiramente, aquela sistematizada em $A$ interpretação dos sonhos (1900/1996), Inconsciente, PréConsciente e Consciente, a chamada primeira tópica. Anos mais tarde, deu-se a formulação de outra variante, em Além do princípio do prazer (1920/1996), como Isso, Eu e Supereu, ou seja, a segunda tópica.

Notamos assim que Freud se dedicou amplamente à pesquisa até formular uma teoria voltada tanto à compreensão do sujeito como para ser um método de tratamento clínico. Diante da continuidade e aprofundamento de seu trabalho como psicanalista e escritor, conforme avançava, não hesitava em voltar atrás e mudar sua posição em relação a algum ponto, antes entendido de um jeito, e depois entendido de outro. A memória foi um tema entre outros que não escapou às suas revisões. Freud concebeu a memória como inconsciente e representacional, e mesmo com as importantes revisões teóricas efetuadas a partir de 1920, tal concepção foi mantida. Nos trechos seguintes, procuramos nos voltar a alguns dentre os primeiros escritos de Freud que sugerem a memória como elemento considerável em suas pesquisas. Textos estes 
anteriores a 1900, isto é, situados, como dissemos, nos chamados anos de publicações pré-psicanalíticas (o período inicial de formulação do pensamento freudiano).

Em correspondência endereçada a Wilhelm Fliess, a chamada Carta 52, Freud (1896/1996) escreve acerca dos estudos até então em curso sobre o psiquismo. Suas investigações encerravam como meta, naquele estágio, entender o mecanismo psíquico. O autor deixa claro que, no período em que escreveu tal carta, ainda restavam várias questões em aberto para chegar a uma elucidação sobre a memória no psiquismo. Apesar dessa sua ressalva, tal escrito se tornou uma das mais importantes referências, no conjunto de seu pensamento, para se buscar uma compreensão da memória. Na carta, Freud (1896/1996) postula que o mecanismo psíquico se formava por processo de estratificação, por isso disposto em diferentes camadas. Desse modo, o material achado como traços seria suscetível a retranscrições de tempos em tempos, consoante circunstâncias diferentes. A novidade quanto ao que havia concebido até então, diz Freud (1896/1996), é a tese segundo a qual a memória não se daria em uma única vez, ao contrário, desdobrar-se-ia por vários tempos.

Em período no qual o peso da neurologia ainda se fazia proeminente em seus estudos, ele escreve na Carta 52 (1896/1996) que haveria uma mútua exclusão entre consciência e memória, uma vez que já havia começado a conceber o inconsciente como uma instância psíquica e a memória como vinculada a essa instância, enquanto que as percepções estariam conectadas à consciência. Em tal carta, Freud faz uso dos termos percepção, consciência, inconsciência e pré-consciência, postulando que diferentes registros seriam colocados em funcionamento através dos neurônios ligados a cada um desses estratos psíquicos. Haveria assim uma raiz perceptiva conectada à consciência dirigida pelo neurônio $W$; um primeiro registro da percepção seria disposto simultaneamente em associações, arranjo executado pelo neurônio $W z$ e dificilmente com aptidão para ascender à consciência. Quanto ao segundo registro - traço Ub (da inconsciência), Freud (1896/1996) sugere que talvez esteja relacionado a lembranças conceituais, impenetráveis à consciência. Um terceiro registro, $V b$, estaria vinculado às representações verbais e equivaleria ao eu. Catexias oriundas de $V b$ atingem o consciente somente através de certas regras. Os neurônios da consciência seriam os mesmos da percepção e, em si mesmos, despidos de memória. Freud (1896/1996) deixa claro na carta o fato de se restringir a uma exposição inacabada até aquele momento, não alcançando uma visão completa dos formatos psíquicos da percepção e dos três registros. Seja acrescentada sua constatação da impossibilidade, na ocasião, em realizar tal exposição, o que caso fizesse, estaria alcançando uma nova modalidade de psicologia. Esta, porém, não era sua pretensão naquele momento.

Freud (1896/1996) define a falha na tradução do material entre os diferentes registros como recalcamento. Tais registros ocorrem em etapas 
contínuas da vida. Entre um registro e outro há uma fronteira. Uma tradução do material psíquico fica impedida de ocorrer entre cada uma das fronteiras por haver um desprazer que opera promovendo certo distúrbio, barrando, consequentemente, $\mathrm{O}$ avanço do registro psíquico à camada seguinte. $O$ recalcamento se dá por uma produção de desprazer que não admite a tradução. No interior de uma mesma fase psíquica e entre registros do mesmo tipo, formase o que Freud (1896/1996) chama de defesa normal que se deve à produção do desprazer. Enquanto isso, o que ele designa por defesa patológica se dá contra um traço de memória de uma fase anterior não traduzido.

Podemos reparar em tal carta que Freud aponta para a memória não como elemento fixo, nem passivo. Ao contrário, a memória é por ele entendida como ativa, isto é, elemento a sofrer influências de tempos em tempos e operar em sua ligação com esses diversos tempos. Isso quer dizer que nossa produção mnêmica está sujeita às influências circunstanciais nas quais estejamos envolvidos. Sendo assim, para Freud (1896/1996), a memória não é exatamente um arquivo ao qual teríamos acesso para trazer ao agora as ocorrências passadas. Não é igualmente um retrato fiel do acontecido. Por seu caráter plástico, a memória estaria sempre sujeita a se recompor em acordo com as condições presentes. Sendo assim, ao atravessar distintos tempos, a memória se mostra flexível a alterações. Não obstante a passagem do tempo - fator que não deve ser desprezado -, o que Freud sublinha como determinante é que os rearranjos da memória se dão em função de uma disposição constitutiva no aparelho psíquico operada pelo recalque e que impede que se reconheçam alguns desejos inconscientes de natureza sexual adversos ao eu moral e consciente.

Com o modelo do recalcamento delineado por Freud o que ocorre é evitar que uma lembrança atravessada por desprazer possa se dar de forma livre. Garcia-Roza (2008), em uma leitura de $A$ interpretação dos sonhos (1900/1996), observa que a lembrança evitada é um processo semelhante à retirada de uma percepção. A memória, portanto, funciona imersa nessa trama psíquica, não passando incólume à operação do modelo do recalcamento efetuado pelo sistema Pré-consciente/Consciente (Psc/Cs) - aquele que cumpre uma função inibidora. Enquanto isso, o que se põe em movimento pelo sistema Inconsciente (Ics) é tão somente o desejo. Vejamos como o comentarista expõe o modelo concebido por Freud:

[...] um determinado processo mental pertencente ao Ics procura acesso à consciência em busca de satisfação. No entanto, a censura que opera na passagem do Ics para o Pcs/Cs opõe-se violentamente a esse propósito, pois a satisfação do desejo inconsciente, que em si mesma provocaria prazer, provocaria também desprazer relativamente às exigências do Pcs/Cs. Por essa razão, o desejo tem de permanecer inconsciente, podendo retornar sob a forma de sintoma. Ocorre, porém, que o material recalcado exerce uma atração constante sobre os conteúdos do Pcs/Cs, em relação aos 
quais ele possa estabelecer uma ligação no sentido de escoar sua energia. Igualmente importante é o fato de que o sistema Pcs/Cs necessita ter acesso a todas as lembranças relativas à experiência passada do indivíduo, e sabemos que, para Freud, essas lembranças se conservam integralmente (Garcia-Roza, 2008, p. 90-91).

No texto O mecanismo psíquico do esquecimento, Freud (1898/1996) escreve que, nos casos de esquecimento, um desprazer contínuo é liberado até o instante em que o problema encontra uma resolução. A tensão se desfaz quando o esquecimento é suplantado através de um apoio exterior. O esquecimento de nomes que se dera com ele próprio consistiu em uma operação do recalcamento. A análise de tal ocorrência em retrospectiva o levou a elaborar que tais nomes e assuntos esquecidos remetiam a dois temas (a morte e o gozo sexual), que surgem representados na fala por fonemas ou grupos de fonemas em uma cadeia de acontecimentos e palavras que se deram durante uma viagem e lhe despertaram interesse.

Tais esquecimentos o fizeram notar que havia um fluxo de representações nele encontrado em estado recalcado e que por força de uma resistência havia o impedimento de uma elaboração, isto é, manifestava-se uma barreira para torná-los conscientes. Fez-se notar no acontecimento todo um jogo de nomes substitutos, vocábulos e fonemas que se encadeavam não de modo explícito. Isso quer dizer que por uma exploração atenta da linguagem, em combinações notadamente complexas para um observador desatento, Freud conseguiu construir a ligação entre tais palavras, as vivências pelas quais passou e o que ficou à primeira vista sem qualquer evidência. Ele observou, assim, o processo mental que opera de modo a resultar em esquecimento, apontando uma vez mais para o papel do recalque no processo de uma dada recordação ou na perda ocasional da memória. Tal fato é por Freud (1898/1996) evocado como exemplo em sua defesa da potência da terapia psicanalítica, pois esta teria por meta, como ele pontua, retificar os recalques e deslocamentos, abolindo os sintomas ao reinstalar o verdadeiro objeto psíquico. No texto em questão, Freud não explicita qual seria esse objeto psíquico ao qual está se referindo. Coelho Jr. (2001) esclarece que a noção de objeto nas formulações teóricas freudianas precisam ser cautelosamente tratadas, pois ao ser usada de múltiplas formas ao longo da sua obra, tal noção participa na construção de muitos entre os principais temas da teoria psicanalítica. Um ponto a ser destacado, logo de primeira, pode ser a relação entre a pulsão sexual e os objetos para os quais se direciona. Freud, de uma maneira geral, remete a objetos que são, de fato, representações psíquicas.

Freud (1898/1996) sublinha que dentre os diversos fatores a impor barreira a uma recordação ou a gerar a aparente perda da memória, o recalcamento cumpre um papel proeminente, não só entre neuróticos, mas também em qualquer pessoa normal. Sendo assim, afirma que uma dada impressão para ser lembrada, fácil e fidedignamente, depende de diversos 
fatores: da constituição psíquica individual, da força da impressão quando recente, do empenho voltado para ela na ocasião, da constelação psíquica no momento, do interesse voltado para sua emergência, das vinculações para as quais a impressão foi arrastada. Freud (1898/1996) chama a atenção para a crença banal de que a memória teria como função ser um acervo acessível e aberto a qualquer pessoa que sinta curiosidade e, assim, sujeita a restrições por uma propensão da vontade, tão precisamente quanto qualquer parcela de nossa atividade que se dirija para o mundo externo. Contrariamente a essa crença, ele afirma que as lacunas da memória, as lembranças que à primeira vista parecem ter se perdido são, de fato, - por seu caráter inconsciente - um não saber que não se quer saber, como ele observou nos casos de histeria. O trabalho psicanalítico, por isso, caracteriza-se como empenho durante seu decurso em preencher os furos da memória. Nesse contexto, constata-se que o resgate das lembranças perdidas encara alguma oposição, a qual nomeia resistência, que justificaria como contrapeso dispor de uma operação proporcional à sua intensidade.

Reparemos que à memória se vinculam tantos outros elementos e que o seu estudo não se deu isoladamente no pensamento freudiano, mas como parte de uma cadeia complexa. A busca por entender o todo da estruturação e funcionamento do psiquismo conduziu Freud à observação de cada elemento em detalhe sem perder de vista o todo. Nesse texto em que trata do mecanismo psíquico do esquecimento, ele aponta que a memória não é passível de controle. Sobre sua evocação operam fatores que não estão na ordem do consciente; fatores estes de outra ordem que nos surpreendem e talvez até incomodem. E o esquecimento é designado como uma espécie de furo que não permite à lembrança surgir com nitidez. Nesse momento das pesquisas freudianas (1898/1996), o trabalho analítico teria como meta superar os furos da memória, transpondo as resistências que impediriam o sujeito de se conectar com sua própria história, trazendo à tona suas lembranças. Façamos assim uma pequena digressão a fim de situar o conceito de resistência no pensamento freudiano.

Cabe ressaltar que a resistência se mostra como conceito relevante no pensamento freudiano, como também na teoria psicanalítica. Freud a pensa de diferentes maneiras em sua trajetória investigativa, de modo que cabe atentarse para a fase na qual ocorre a teorização desse conceito ao longo dos seus escritos. Freud (1898/1996) concebe a resistência como algo a ser suplantado em nome da saúde do sujeito e afirma que, no fato mesmo de esquecer, operam o recalcamento e o deslocamento. O trabalho psicanalítico, para ele, consistiria em superar tais barreiras ao buscar na mente as memórias obscurecidas que teriam o poder de levar o sujeito a se ver livre do seu sintoma. Acresce dizer que resistência é, entre outros, um conceito caracterizado pela multiplicidade no pensamento de Freud, comportando em diferentes tipos, como considera Canavêz (2012). Freud o desenvolve ao longo de sua obra, ampliando e 
aprofundando seu entendimento. Sua concepção na chamada fase dos textos pré-psicanalíticos diz respeito à pretensão de superá-la ao tornar consciente o inconsciente, suplantando o esquecimento. Freud pautava-se, naquele momento, na ideia de que no processo clínico chegaria à remissão sintomática através da rememoração.

Conforme Canavêz (2012), na formulação metapsicológica de Freud, o aparelho psíquico é concebido em uma dimensão tríplice: tópica, dinâmica e econômica. Na fase da psicanálise em que eram tecidas suas bases teóricometodológicas, a técnica remetia à necessidade de superação da resistência, percebida nesse momento como barreira ao êxito clínico. À interpretação do analista caberia tornar consciente 0 inconsciente, operando uma modificação tópica no aparelho psíquico. Desse modo, segundo Canavêz (2015), Freud pensou a resistência como forma de defesa em face da iminente evidência dos conteúdos opostos à moral presente na sociedade de então. Tal expressão defensiva, a princípio, precisava ser superada para tornar possível a supressão dos sintomas histéricos.

Em seus escritos mais tardios, porém, Freud passou a compor tal questão de outro modo. Assim, aponta Canavêz (2015), ele observou que mesmo com todo esforço investido pelo analista, a resistência não cessa, abrangendo o aparelho psíquico por inteiro. Com tal entendimento, já no contexto da segunda tópica (Freud, 1925/1996), diferentes resistências são reconhecidas (do isso, do eu e do supereu), de maneira que no funcionamento do aparelho psíquico há multiplicidade de resistências.

Canavêz e Herzog (2012) chamam a atenção para o fato de que frente aos impasses presentes em sua clínica, já em 1920, sob influência do trauma elemento que não se mostrava passível à interpretação do analista e acabou se tornando fundamental para que houvesse outras formulações na teoria e na clínica tal como construídas por Freud -, em lugar da preponderância da tópica enquanto dimensão psíquica a ser alvo de mudança, o que se demonstrou insuficiente, passaram a valer as dimensões dinâmica e econômica. Com isso, Freud se viu impelido a buscar alterações em relação ao pensamento e construção do trabalho clínico, levando em conta as expressões de mal-estar reconhecidas à época.

Sendo assim, Canavêz (2015) alude à resistência no sentido de força que coloca em movimento tanto o trabalho analítico quanto o próprio processo de subjetivação. Tais observações em relação ao conceito de resistência se tornam ainda mais válidas no presente texto não apenas por nos fornecer condições de uma visão atenta a essa importante questão em específico presente na clínica, uma vez que também nos ajuda na atenção para com a importância das conexões conceituais estabelecidas no âmbito do pensamento freudiano. Exemplos disso são as compreensões acerca da relação da resistência com o esquecimento e $\mathrm{o}$ ato mesmo de lembrar; relação também vista quanto ao 
recalque e ao sintoma. Além disso, põe-nos em alerta para a própria compreensão da memória como conceito que também sofreu mudanças ao longo dos diversos momentos da obra freudiana.

O esquecimento, como diz Gondar (2000), configura-se como enigma ainda maior do que a lembrança. Curiosamente, é corrente tratarmos com alguma indiferença o fato de lembranças da nossa infância ficarem de certo modo perdidas. Comentário este pertinente, pois com Freud (1898/1996) sabemos que o esquecer não se dá à toa. Nessa ocorrência tão comum para qualquer um de nós operam interferências vigorosas no psiquismo, quais sejam, o recalcamento e a resistência. Segundo Gondar (2000), o próprio recalcamento pode ser encarado como um ato de esquecimento, enquanto que a resistência se soma como força que bloqueia o surgimento da lembrança.

No texto Lembranças encobridoras, Freud (1899/1996) pondera que as lembranças infantis notabilizam o funcionamento psíquico diverso entre adultos e crianças e considera que os primeiros anos de vida marcam consideravelmente nossa mente. Vejamos sua explicitação do assunto:

[...] o tema das lembranças da infância está, de qualquer modo, destinado a ser de interesse psicológico, pois elas põem em notável relevo uma diferença fundamental entre o funcionamento psíquico das crianças e dos adultos. Ninguém contesta o fato de que as experiências dos primeiros anos de nossa infância deixam traços inerradicáveis nas profundezas de nossa mente. Entretanto, ao procurarmos averiguar em nossa memória quais as impressões que se destinaram a influenciar-nos até o fim da vida, o resultado é, ou absolutamente nada, ou um número relativamente pequeno de recordações isoladas, que são freqüentemente de importância duvidosa ou enigmática (Freud 1899/1996, p. 287).

Podemos reparar que Freud chama a atenção para dois fenômenos interessantes. Em primeiro lugar, a afirmação de que os primeiros anos de vida nos marcam de maneira intensa. $E$, em segundo lugar, todos nós curiosamente temos, à primeira vista e apenas aparentemente, poucas recordações dessa fase, uma vez que de algum modo as lembranças habitam nossas profundezas mentais. Ora, a assertiva freudiana sobre a infância é marcante, sendo uma entre outras que exerceu notória influência sobre os mais variados estudos em psicologia. Ao longo de sua obra, sob diferentes temas, os anos da infância serão alvo de pesquisa. Os relatos - em análise - dos seus pacientes acerca das vivências infantis e das lembranças construídas sobre essa etapa da vida contribuíram sobremaneira na sistematização de sua teoria. Lembranças essas de caráter marcadamente fantasioso, isto é, não exatamente factuais ou algumas vezes até mesmo nada factuais, como Freud deixa claro na Carta 69 (1897/1996) escrita a Fliess. Em tal carta, Freud descreve as razões pelas quais passou a não mais acreditar em sua neurótica. Entre essas razões, pondera que se o relato da sedução paterna tal como expresso pelas histéricas fosse real, haveria quantidade significativamente alta de homens (pais) pervertidos, o que a 
certa altura soou a Freud como algo absurdo e improvável. Também por já ter suficiente conhecimento acerca do funcionamento do inconsciente que the permitiu constatar que neste não haveria indicativos da realidade. Soma-se ainda o fato de que a resistência do consciente não permitiria que se tornasse claro o conteúdo inconsciente e, por isso, tais neuróticas não seriam capazes de lembrar a suposta ação do sedutor. Nessa esteira, podemos considerar que o olhar voltado ao passado, mesmo baseado em fatos, encontra-se permeado por uma evocação fantasiosa, conforme as construções mentais sedimentadas ao longo da vida. Nessa trama, há restos esquecidos ou ausentes, mas apenas aparentemente, já que se mostra suscetível a manifestações ao longo da vida do sujeito.

Conforme declaram Canavêz e Herzog (2007), antes de chegar a essa conclusão, Freud acreditara que o agir do adulto, no caso o pai da neurótica, seria o ponto inicial da neurose. Ao ouvir suas pacientes histéricas, o relato de uma vivência assim tão intensa (a sedução por um adulto) restou reconhecida como trauma psíquico. Há uma mudança significativa em relação à medicina da sua época que Freud introduz quanto a essas constatações, que foi considerar a fala dessas pacientes, reconhecendo nelas todo peso da realidade psíquica e não a factual, concedendo assim um lugar de importância à ficção construída pelo sujeito. Anos depois da emblemática Carta 52 dirigida a Fliess, nos Três ensaios sobre a teoria da sexualidade (1905/1996), Freud atesta que fantasiar cumpria a função de tornar encoberto o autoerotismo da infância, que para ele evidenciava uma sexualidade já presente nas crianças bem pequenas. Essa construção teórica serviu de acabamento no abandono da sedução factual enquanto teoria aceitável. Em sua concepção inovadora acerca da constituição do psiquismo, contrapondo-se à medicina em voga, Freud desconsiderou a possibilidade de se constatar uma origem (como uma causa) da neurose, mas passa a considerar um começo que se constitui por meio da fantasia.

Pois bem, em Lembranças encobridoras (1899/1996), o precursor da psicanálise insere este conceito que dá título ao texto, o qual consiste na representação na memória de impressões e pensamentos de período ulterior cujo teor a memória se conecta por ligações simbólicas ou similares. Em outras palavras, o valor de tal lembrança não habita precisamente em seu conteúdo, mas nas vinculações encontradas entre tal conteúdo e outro que tenha sido abolido. Assim, elementos não fundamentais - a posteriori - funcionam como representações de determinadas lembranças infantis que são disfarçadas quanto ao seu real significado. A memória, assim, altera plasticamente seus conteúdos. Trata-se, segundo Freud (1899/1996), do recalque que se faz acompanhar de um elemento substituto próximo em termos de tempo e espaço.

Embora não possa haver garantia qualquer em relação aos dados que a memória produz, uma cena autêntica da infância pode se fazer atuante. Cena esta selecionada dentre tantas outras a fim de servir como representante de uma 
fantasia construída em um momento posterior da vida do sujeito, em uma situação marcada por algum conflito importante para si que é encoberto pela lembrança que remete à infância. No exemplo relatado por Freud (1899/1996) estão presentes na lembrança encobridora aquelas que para ele são as duas maiores forças motivacionais (a fome e o amor). Enquanto a fome pode ser mais facilmente interpretada nas lembranças, o amor se faz mais intensamente encoberto, uma vez que nada como uma cena infantil - por ser encarada como inocente - e, assim, aparentemente se opor a um conteúdo de natureza sexual que se fez recalcado.

$\mathrm{Na}$ escrita de tal texto, Freud já demonstrara ter certa clareza de que suas investigações o conduziam à produção de um novo tipo de conhecimento (a psicanálise), pois se inclina a divulgar suas descobertas em relação ao psiquismo, configurando-o em sistemas diferentes e conflitantes entre si (o Inconsciente e o Pré-consciente/Consciente). Podemos afirmar que nesse momento ele já se encontrava suficientemente convencido das condições para propor uma teoria nova com vistas a entender o sujeito e atribuir-se a tarefa de tratá-lo psicologicamente, ainda que tal teoria fosse incipiente e, notadamente, inacabada. Como a história demonstra, sua teoria teria que contar com uma formulação necessariamente lenta e laboriosa. Em 1899, quando escreve Lembranças encobridoras, Freud já havia escrito quase inteiramente A interpretação dos sonhos (publicada em 1900). Nessa obra, a sistematização da estrutura e funcionamento do aparelho psíquico é elaborada com densidade, vindo a ser reconhecida - alguns anos depois - como a obra magistral na qual a psicanálise é lançada como um saber inovador e como um método notável de tratamento psíquico.

Assim é que Freud (1899/1996) assegura alcançar êxito, não poucas vezes, através do tratamento psicanalítico. Ele acreditava, na ocasião, que chegaria a desvendar as partes faltantes na experiência infantil. Com isso, defende evidenciar que a impressão detida apenas em fragmento na memória, se restaurada na íntegra, confirma o pressuposto de que as coisas mais importantes são as recordadas. Contudo, o pai da psicanálise observa que esse evento não elucida a triagem feita pela memória entre os dados da experiência. Diante de fato tão curioso, Freud (1899/1996) pergunta por que retemos o que é irrelevante e não o contrário. Para desvendar tal questão, escreve ele, é necessário averiguar em profundidade o mecanismo desses processos. Oferece como explicação haver duas forças aí envolvidas; duas forças que se contrapõem, mas não se invalidam (a primeira força atua a partir do inconsciente, enquanto que a segunda atua a partir do consciente). A primeira acha na experiência um motor para lembrar, enquanto que, a outra (uma resistência) procura evitar que a lembrança de fato marcante possa se demonstrar clara e nitidamente. Diz Freud (1899/1996) que também não há prevalência de uma sobre a outra sem que haja uma perda para si própria. 
O que ocorre é uma conciliação que funciona de tal modo que o conteúdo armazenado como imagem mnêmica não é a experiência proeminente em si - aí o que está sobressaindo é a resistência - mas, um outro elemento psíquico fortemente conexo ao elemento passível de oposição. Deve-se esclarecer que o primeiro elemento demonstra vigor e o que deriva do conflito é o seguinte: em lugar da imagem mnêmica que seria nítida pelo evento original produz-se outra que estando associada, até certo ponto, desloca-se da original. Trata-se do deslocamento de algo conexo por extensão. Se o processo for examinado como um todo, afirma-se que é um recalcamento substituído por algo achegado nos marcos de tempo e espaço. Freud, em suas próprias palavras, atesta que o conceito de lembrança encobridora

\begin{abstract}
[...] deve seu valor enquanto lembrança não a seu próprio conteúdo, mas às relações existentes entre esse conteúdo e algum outro que tenha sido suprimido. É possível distinguir diferentes classes de lembranças encobridoras, conforme a natureza dessa relação. Encontramos exemplos de duas dessas classes entre o que se descreve como as primeiras lembranças da infância - isto é, se incluirmos na categoria de lembranças encobridoras as cenas infantis incompletas, que são inocentes justamente por sua incompletude. Pode-se prever que as lembranças encobridoras também hão de ser formadas de resíduos de lembranças relativas a etapas posteriores da vida. Quem quer que tenha em mente seu traço característico - a saber, que elas são extremamente bem lembradas, mas seu conteúdo é completamente irrelevante - evocará facilmente vários exemplos dessa espécie de sua própria memória (Freud, 1899/1996, p. 297-298).
\end{abstract}

Podemos com isso admitir que a firme confiança que possamos ter em certas lembranças supostamente provindas da infância ou mesmo da fase adulta, encarando-as como expressão de uma verdade nua e crua, cai por terra diante da consideração freudiana de que tal fenômeno psíquico está imbricado no processo inconsciente que sobressai em cada sujeito. Não convém, assim, que tais lembranças sejam ingenuamente apreciadas como a mais pura manifestação de pensamentos e afetos tão somente relativos àquele acontecimento ou originários dele. Essa visão pueril é alicerçada, diga-se de passagem, no senso comum de que lembramos algo com fidedignidade ou simplesmente esquecemos em função da passagem do tempo. Diversamente, as alusões a episódios pelos quais tenhamos real ou supostamente passado e a maneira como enfim passamos e, mais tarde, como as reconstruímos na imaginação são, desse modo, advindas de uma trama psíquica que acarreta o processo de construção de uma lembrança e, também, a manifestação do esquecimento.

Tal processo é por Freud (1899/1996) esquematizado da seguinte forma: conflito $>$ recalcamento $>$ substituição. O processo envolve conciliação regressa nos sintomas psiconeuróticos e dão a chave para o entendimento de seu início. Freud (1899/1996) atesta, em relação ao contexto de pesquisas psicológicas de sua época, para o fato de que tal funcionamento psíquico é de grande 
importância. Isto é, os processos defensivos, tanto os patológicos quanto os normais e os deslocamentos a que chegam, não teriam sido pesquisados e, consequentemente, estariam ainda obscuros.

As chamadas lembranças encobridoras enviam tanto à infância, em cenas incompletas, quanto a tempos mais tardios da vida. E Freud (1899/1996) chama a atenção para um dado curioso, na maior parte das cenas importantes da infância, o sujeito vê a si mesmo como criança, sabendo que essa criança é ele próprio. Contudo, a criança é vista como a veria qualquer outro observador externo à cena.

Freud $(1899 / 1996)$ alerta para o fato de que tais lembranças não podem ser, de forma alguma, tais como a impressão original recebida, uma vez que na ocasião o sujeito estava imerso na situação e não focava atenção em si mesmo, mas no mundo externo. Desse modo, Freud (1899/1996) assinala que quando alguém na lembrança surge como objeto entre outros objetos, estarão em contraste o eu que atua e o eu que recorda, sendo essa uma amostra de que a impressão original restou elaborada. Um traço mnêmico infantil é retraduzido em etapa ulterior - aquela em que a lembrança foi acordada. No entanto, adverte Freud (1899/1996), qualquer reprodução da impressão original nunca adentrou a consciência. Com tal descrição e teorização, Freud(1899/1996) elucida que os conteúdos contidos na memória - traços mnêmicos e representações - são marcadamente expressos com mobilidade e plasticidade intimamente ligadas ao inconsciente e à história do sujeito, como também à sua condição presente no ato de lembrar.

Em diversas lembranças de experiências importantes da infância, límpidas e claras, localizam-se cenas enganosas, uma vez verificadas pelas recordações dos adultos. Freud (1899/1996) destaca não se tratar, nesses casos, de invenções, pois são enganosas por terem transportado um evento para onde ele não ocorreu. Uma investigação em detalhe leva a constatar que os enganos da memória são tendenciosos, pois se prestam ao recalque e deslocamento de impressões abjetáveis e desagradáveis operadas pelo eu. Tais lembranças enganosas se iniciaram em etapa da vida na qual se tornou possível aferir um lugar na vida mental a essa modalidade de conflitos e aos impulsos de recalcamento, sendo, assim, bem ulterior à etapa a que pertence seu conteúdo. Essa modalidade de lembrança enganosa é a primeira que passamos a conhecer, porém a matéria-prima dos traços mnêmicos que a formaram se mantém enigmática em sua condição inicial.

Temos assim que um dos elementos encadeados à memória - e também muito importante na teoria psicanalítica - é o tempo. O que Freud parece nos dizer é que os três tempos: passado, presente e futuro são separados somente até certo ponto. Nós os organizamos, separamos e sobre eles falamos como apartados. Tal modo de entender e discursar atrela-se ao nosso nível consciente, com o qual podemos ter a ilusão de que os diversos tempos são assim mesmo, 
separados e reservados cada qual a um suposto seu lugar. No funcionamento psíquico, entretanto, opera com proeminência o inconsciente, instância em que os três tempos se atravessam mutuamente, vindo a exercer interferência um sobre o outro. Assim, o que passou não exatamente é passado; o que é presente não pertence só ao hoje, pois se liga ao passado, atualizando-o e redesenhandoo de algum modo, em acordo com as circunstâncias sob as quais nos situamos. Acresce dizer que $o$ passado e $o$ presente servirão de base para os desdobramentos daquilo que ainda viveremos, o que chamamos futuro. Ora, a memória se constrói e opera é exatamente aí, como inseparável do fator tempo. Assim é que, no ato de lembrar, como sublinha Freud (1899/1996), produzimos um conteúdo psíquico que pode nos levar a crer ser uma vívida recordação de um episódio infantil, mas que de fato fora produzido em momento tardio, uma vez que o recalcamento e o deslocamento mostram-se atuantes.

O conhecimento de tal fato, escreve Freud (1899/1996), deve nos levar a abreviar a diferenciação que postulamos para as lembranças encobridoras e outras formas de lembranças oriundas da vida infantil. Freud (1899/1996) argumenta, nesse sentido, se será mesmo possível que haja lembranças provindas da infância. Talvez, diz ele, o que chegamos a ter são apenas lembranças relativas à etapa infantil. Logo, as lembranças da infância não nos exibem essa fase tal como foi realizada, e sim como se expõe em períodos ulteriores nos quais essas lembranças restaram acordadas. Nas etapas de vida em que se exibiram, essas lembranças não vieram à tona tal como é comum afirmar. E aí Freud (1899/1996) surpreende ao inferir que tais lembranças foram construídas nessa etapa tardia. Escreve ele que se preocupar com a história em sua precisão é justamente o que não ocorre, uma vez que há um artifício que tem parte nas lembranças formadas e selecionadas.

Como postula Farias (2008), podemos com isso notar um vínculo íntimo entre os conceitos de memória e "a posteriori", que aponta para certa distância entre um dado acontecimento e a lembrança que sobre este se formou, posto que uma lembrança não remete tão somente ao passado. Tais assertivas freudianas nos fornecem indicações eloquentes para compreender que a memória se configura pela ligação entre o que lembramos e o que esquecemos. Pela memória, em seu intrínseco caráter inconsciente, podemos vislumbrar que determinados conteúdos, de forma inelutável, extrapolam nosso saber.

\section{CONSIDERAÇÕES FINAIS}

Após discorrer de forma introdutória acerca do teor inédito do pensamento freudiano, tivemos como alvo desse estudo sua concepção inicial sobre a memória na trama da constituição psíquica. Observamos, assim, que Freud inaugura uma forma original de conceber o sujeito. 
Com base em alguns dentre os seus textos pré-psicanalíticos, procedemos com uma busca do lugar que o tema memória ocupou naquele período do conjunto mais amplo da pesquisa sobre o psiquismo e, por consequência, sobre a constituição do sujeito. Expomos, desse modo, um panorama das investigações freudianas acerca da memória até parte de 1899, ano que marcará a escrita de $A$ interpretação dos sonhos (1900/1996), obra lançada no ano seguinte e não explorada neste texto por sua reconhecida condição de marca inaugural da fase psicanalítica, propriamente dita, do trabalho de Freud.

Ao percorrer o tema da memória em alguns textos da fase prépsicanalítica do pensamento freudiano, podemos afirmar que encontramos algo categoricamente incomum ao final do século XIX, isto é, uma maneira inovadora de conceber a subjetividade. Trabalho teórico-clínico que adentrou o século $X X$, situando-se em um lugar entre especificamente particular. Um lugar entre a medicina e a jovem psicologia científica, tornando-se um saber diferente daqueles então conhecidos.

Em meio às pesquisas e assertivas de Freud em sua trajetória teóricoclínica, por sua persistência em tentar desvendar a constituição e o funcionamento do psiquismo e promover o cuidado dos sujeitos, entre outros elementos importantes, encontra-se a memória, tema que mereceu sua atenção e para o qual direcionou uma parte importante do seu trabalho. Com efeito, a psicanálise se colocou como teoria e método clínico que inovou o olhar e o entendimento sobre o que constitui o sujeito, em seu indelével entrelace com a cultura da qual é participante. Sujeito este constituído pelo inconsciente, instância psíquica a mais relevante em nossa forma de construir memória.

\section{REFERÊNCIAS}

Antonello, D. F., \& Herzog, R. (2012). A memória na obra freudiana, para além da representação. Arquivos Brasileiros de Psicologia, Rio de Janeiro, 64 (1), 111-121.

Batista, W. J. (2007). A superfície inacessível: fundações do pensamento ocidental. Rio de Janeiro, RJ: Letra Capital.

Birman, J. (2006). Arquivos do mal-estar e da resistência. Rio de Janeiro, RJ: Civilização Brasileira.

Canavêz, F. (2012). Violência, trauma e resistência: sobre o múltiplo na psicanálise (Tese de Doutorado). Programa de Pós-Graduação em Teoria Psicanalítica, Universidade Federal do Rio de Janeiro, Rio de Janeiro.

Canavêz, F. (2015). Entre Freud e Foucault: a resistência como afirmação de si. Psicologia Clínica, Rio de Janeiro, 27(1), 225-244. doi: 10.1590/010356652015000100013. 
Canavêz, F., \& Herzog, R. (2007). A singularidade do sintoma: por uma crítica psicanalítica à idéia de origem. Psicologia Clínica, Rio de Janeiro, 19(1), 109-124. doi: 10.1590/S0103-56652007000100008.

Caropreso, F. (2006). A relação entre a memória, a percepção e a consciência na metapsicologia freudiana. AdVerbun, Campinas, 1(1), 12-22.

Coelho Jr., N. E. (2001). A noção de objeto na psicanálise freudiana. Ágora: Estudos em Teoria Psicanalítica, Rio de Janeiro, 4(2), 37-49. doi: 10.1590/S1516-14982001000200003.

Ferrarini, P. P. F. L., \& Magalhães, L. D. R. (2014). O conceito de memória na obra freudiana: breves explanações. Estudos Interdisciplinares em Psicologia, Londrina, 5(1), 109-118. doi: 10.5433/22366407.2014v5n1p109.

Freud, S. (1895/1996). Projeto para uma psicologia científica. In: Obras Psicológicas de Sigmund Freud. (Vol. 1, pp. 333-443). Rio de Janeiro, RJ: Imago. (Trabalho original publicado em 1950).

Freud, S. (1896/1996). Carta 52. In: Obras Psicológicas de Sigmund Freud. (Vol. 1 , pp. 281-287). Rio de Janeiro, RJ: Imago. (Trabalho original publicado em 1950).

Freud, S. (1897/1996). Carta 69. In: Obras Psicológicas de Sigmund Freud. (Vol. 1, pp. 350-351). Rio de Janeiro, RJ: Imago. (Trabalho original publicado em 1950).

Freud, S. (1898/1996). O mecanismo psíquico do esquecimento. In: Obras Psicológicas de Sigmund Freud. (Vol. 3, pp. 249-284). Rio de Janeiro, RJ: Imago. (Trabalho original publicado em 1950).

Freud, S. (1899/1996). Lembranças encobridoras. In: Obras Psicológicas de Sigmund Freud. (Vol. 3, pp. 285-306). Rio de Janeiro, RJ: Imago. (Trabalho original publicado em 1950).

Freud, S. (1996). A interpretação dos sonhos. In: Obras Psicológicas de Sigmund Freud. (Vol. 4-5). Rio de Janeiro, RJ: Imago. (Trabalho original publicado em 1900).

Freud, S. (1996). Três ensaios sobre a teoria da sexualidade. In: Obras Psicológicas de Sigmund Freud. (Vol. 7, pp. 163-195). Rio de Janeiro, RJ: Imago. (Trabalho original publicado em 1905).

Freud, S. (1996). Leonardo da Vinci e uma lembrança da sua infância. In: Obras Psicológicas de Sigmund Freud. (Vol. 11, pp. 73-142). Rio de Janeiro, RJ: Imago. (Trabalho original publicado em 1910).

Freud, S. (1996). Recordar, repetir e elaborar: novas recomendações sobre a técnica da psicanálise. In: Obras Psicológicas de Sigmund Freud. (Vol. 12, pp. 159-172). Rio de Janeiro, RJ: Imago. (Trabalho original publicado em 1914). 
Freud, S. (1996). Os instintos e suas vicissitudes. In: Obras Psicológicas de Sigmund Freud. (Vol. 14, pp. 115-144). Rio de Janeiro, RJ: Imago. (Trabalho original publicado em 1915).

Freud, S. (1996). Repressão. In: Obras Psicológicas de Sigmund Freud. (Vol. 14, pp. 145-162). Rio de Janeiro, RJ: Imago. (Trabalho original publicado em 1915).

Freud, S. (1996). O inconsciente. In: Obras Psicológicas de Sigmund Freud. (Vol. 14, pp. 165-224). Rio de Janeiro, RJ: Imago. (Trabalho original publicado em 1915).

Freud, S. (1996). Além do princípio do prazer. In: Obras Psicológicas de Sigmund Freud. (Vol. 18, pp. 11-75). Rio de Janeiro, RJ: Imago. (Trabalho original publicado em 1920).

Freud, S. (1996). Uma nota sobre o bloco mágico. In: Obras Psicológicas de Sigmund Freud. (Vol. 19, pp. 253-262). Rio de Janeiro, RJ: Imago. (Trabalho original publicado em 1925).

Freud, S. (1996). Construções em análise. In: Obras Psicológicas de Sigmund Freud. (Vol. 23, pp. 271-287). Rio de Janeiro, RJ: Imago. (Trabalho original publicado em 1937).

Garcia-Roza, L. A. (2008). Freud e o inconsciente (23. edição). Rio de Janeiro, $\mathrm{RJ}$ : Zahar.

Gondar, J. (2000). Lembrar e esquecer: desejo de memória. In: Costa, I. T. M. \& Gondar, J. (orgs.). Memória e espaço (pp. 35-43). Rio de Janeiro, RJ: 7Letras.

Japiassú, H., \& Marcondes, D. (2006). Dicionário básico de filosofia (4. edição). Rio de Janeiro, RJ: Zahar.

Santos, L. B. (2008). Sobre a memória em Freud: uma introdução. Língua, Literatura e Ensino, Campinas, (3), 491-497.

Zavaroni, D. M. L.; Viana, T. C. e Celes, L. A. M. (2007). A constituição do infantil na obra de Freud. Estudos de Psicologia, Natal, 12(1), 65-70. doi: 10.1590/S1413-294X2007000100008. 
Sobre os autores

Wallace da Costa Brito é psicólogo pela UNIABEU Centro Universitário;

mestrando no Programa de Pós-Graduação em Psicologia da Universidade Federal Rural do Rio de Janeiro (PPGPSI/UFRRJ). e-mail:

wallacedacostabrito@gmail.com

Fernanda Canavêz é psicóloga pela Universidade Federal do Rio de Janeiro (UFRJ); mestre e doutora pelo Programa de Pós-Graduação em Teoria Psicanalítica da Universidade Federal do Rio de Janeiro (PPGTP-UFRJ); professora adjunta do Departamento de Psicologia (DEPSI/UFRRJ) e do Programa de PósGraduação em Psicologia da Universidade Federal Rural do Rio de Janeiro (PPGPSI/UFRRJ). e-mail: fernandacanavez@gmail.com

Recebido em: 05/04/2016 $1^{\text {a }}$ revisão em: 14/06/2016 2a revisão em: 06/09/2016

Aceito em: 30/10/2016 